\title{
Would You Have Realized?
}

Learning is a game. In this sense, Dermatology + Psychosomatics regularly presents you the Psychodermatology Quiz. Other colleagues are welcome to submit their own contributions.

\author{
C.-M. Höring ${ }^{a} \quad$ G. Nist ${ }^{b}$ \\ a Dermatological Practice \\ ${ }^{b}$ Department of Dermatology, City Hospital Bad Cannstatt, Stuttgart
}

\section{Case Description}

Mrs. M., 43 years old, was hospitalized because of recurrent candidiasis of the vulvogenital area. First symptoms had appeared after a visit in a public bath when she was 17 years old. At that time symptoms had been aggravated by the therapy with several antimycotics, so that only after an additional contact allergy had been diagnosed she was treated successfully. She had then been healthy until 1983, when again similar complaints occurred after a bath in a lake. The vulvogenital area had been horribly swollen and itching, and the symptoms were difficult to treat. No local or systemic antimycotic therapy brought improvement. During the past few years, $200 \mathrm{mg}$ of local corticoids had been necessary to improve the eczema, but since then she feels extremely sensitive in that area. In November 2001 a vaginal smear again showed a candida infection, but ketoconazole cream did not help. An atopic diathesis is known with pollinosis and asthma.

When Mrs. M. came to hospital the examination and the vaginal smear showed no pathological findings. No vaginal eczema. So local therapy consisted only of indifferent topical preparations like unguentum molle. An additional examination by a gynecologist brought no further diagnoses.

When Mrs. M. presents in the psychosomatic counseling she describes her story rather expressively, and she emphasizes her helplessness and her anxiety: 'I can feel it as if it was yesterday.' She says that she continuously has problems like candida infections, itching and hypersensitivity of the genitoanal region since she gave birth to her two children ( 9 and 6.5 years old). She can only cope with the complaints by avoiding sexual intercourse and by wearing loose clothes.

This is the moment to develop a first hypothesis of problems concerning her marriage. As Mrs. M. also complains about fatigue, fragile fingernails and hair loss, it seems easy to inform her about connections between somatic defense mechanisms, 'stress', and psychological defense mechanisms - apparently she does not feel very attractive and healthy. She confirms that her marriage is at a turning point.

She grew up very protected: 'My mother has been the only one who was always present for me. She has dedicated her life to me and my brother.' Mrs. M. is a woman with many fears. Stress like exams had been terrible for her, she regularly suffered from severe bronchial infections after exams. So when she married she hoped to have a husband as caring as her mother was. She adored him. During the first years of their marriage he indeed took care of her and they spent a lot of time together. But then he became successful in his job and it seemed to her that he did not have time for her anymore. After the birth of her children she realized that she had to care for them alone, and more and more she felt disappointed. 'Everybody wants something from me, nobody looks after me.' Instead of searching for ways to make her life more pleasant, she suppresses her anger and develops perfectionism in her household, which makes her more and more discontent. 'I am like my mother. She was always working and cleaning and she had gastric ulcers.' She completes her description: 'My daughter is bleeding me white, she is extremely demanding.'

Mrs. M. considers a divorce, but she knows that she would feel unable to live alone with her children.

\section{Questions}

1) What are your first ideas from a psychodynamic point of view?

2) Which psychopathological diagnosis would you suggest?

3) Can you identify a conflict?

4) Which therapy would you recommend in addition to the dermatological somatic treatment, which procedure seems efficient?

\begin{tabular}{ll}
\hline KARGER & @ 2002 S. Karger GmbH, Freiburg \\
Fax +497614520714 & Accessible online at: \\
$\begin{array}{l}\text { E-mail Information@Karger.de } \\
\text { www.karger.com }\end{array}$ & www.karger.com/journals/dps
\end{tabular}

Dr. Christa-Maria Höring 


\section{Answers}

1) Mrs. M. tells her story in a very expressive manner. She is tortured by her symptoms, she feels helpless - and she gives a hint when she describes her coping mechanisms to deal with the problem: not to have sexual intercourse. She does not seem to be depressive; she has got a somatic predisposition of atopy so that it seems probable to develop eczema when she is stressed, beyond other biological triggers like recurrent infections, mechanical irritation, etc. She already knew that she was prone to develop infections of the bronchial system and asthmoid reactions in connection with personal stress.

As she feels extremely disappointed in her marriage, her body 'chooses' a reaction in the genital area which allows her to avoid intimate contact instead of solving her problems. On the one hand, she can punish her husband in this way, on the other hand it seems to express that in fact she does not feel like an adult woman in her partnership. She feels like a 'girl' who only wants to be 'fed' and protected as she had been by her mother. She tells this story indirectly when she talks about her 'demanding daughter' - she projects her own desires on the child and seems to rival with her, unable to give her what a mother should give.

2) Atopic eczema of the vulval and anal area and recurrent candidiasis with exacerbation by psychosocial problems (ICD F 54.0, ICD F 20.8); conversion neurosis with symbolic expression in the genital area following a partnership problem; e.g., mixed narcissistic and phobic personality.

3) There are different conflicts. It is obvious that a conflict of separation exists, which seems to be both an early conflict concerning her phobic personality traits that means separation from a 'mother', a protecting person (these wishes are unconsciously directed to her husband) and also a more mature conflict of oedipal character and secondary neurotization (nothing is known about her relationship to her father). There is also a conflict between her needs to be 'fed' and dependent and her wishes for autonomy. Before she was married, Mrs. M. had had a lot of leisure activities and social contacts.

There also seems to be an aggression conflict - she 'prefers' a somatic solution instead of solving the partnership problems by means of marriage counseling or by fighting for her wishes like more familial engagement of her husband.

4) Mrs. M. was informed about possible psychosocial connections. She was proposed to take up her hobbies like sports and to care for herself with the adult part of her personality. Because of the chronic course and the experience of failure of all treatment and her own coping possibilities and because of the complex psychodynamic back- ground she was recommended a long-term psychodynamic psychotherapy and e.g., a marriage counseling for her and her husband. Mrs. M. was very interested in these proposals.

\section{Key Learning Points}

\section{Conversion Neurosis}

Conversion is a symptom of psychogenic origin, which represents a compromise between unconscious wishes, fantasies, ideas, and the mechanisms that try not to allow them to become conscious. All the feelings like anger, aggression, shame, disgust etc. seem to be so unbearable that the individual 'prefers' a somatic symptom.

The fantasies, wishes, and ideas are symbolically expressed by means of the body. So, for example, a symptom in the genital area allows to avoid sexually mature contact and to return to a mode of infantility.

Stress is reduced, but the disease punishes the individual with pain, itching etc. Another profit might be that the relatives take more care of the person. Symptoms occur predominantly in areas which are capable of 'communication'. For pruritus vulvae Koblenzer [1987] reveals frustration of the sexual life as a prominent psychodynamic formulation.

\section{Separation Conflict}

Patients with neurotic anxiety might fear to loose the love of their partner or other important persons, but even more to loose themselves by the loss of somebody else. 'I am missing somebody very important - I am missing a part of myself.' They are not really sure about the constancy of the objects. So it is quite difficult to live aggressive feelings, which might support a separation. Psychosomatic symptoms represent a compromise, they allow to feel one's own body instead of panic. Typically, these patients live in relationships in which they adore the partner, and they are extremely disappointed when the partner withdraws from them and wants more autonomy then the patients develop symptoms of loss anxiety. One aspect of the background is the absence of empathy, the disability to get an idea of the feelings and the experiences of their vis-à-vis.

\section{Suggested Reading}

Mentzos S (Hrsg): Angstneurose. Psychodynamische und psychotherapeutische Aspekte. Geist und Psyche. Frankfurt, Fischer, 1991.

Koblenzer CS: Psychocutaneous Disease. New York, Grune and Stratton, 1987. 